\title{
Opposition Relationship in Handball and the Constant Reversibility of Attack and Defense
}

\author{
By Zeineb Zerai, Chedlia Fitouri ${ }^{ \pm}$, Ali khalifa Alshamli ${ }^{+}$\& \\ Hafsi Bedhioufi
}

In opposition to the principles of traditional pedagogy which values the acquisition of gestural models through a technical approach, this article develops a theory of intervention based on the opposition between two teams, involving a logic of tactical decision-making and a succession of relevant tactical choices in attack and defense. By focusing on the fluctuations in the links between attack and defense, it thus presents a system of the main actions in handball, that is to say in this case a set of principles closely dependent on each other, constituting a whole of deep logical unity. With its functional character, this approach is based on a modeling of game play where the opposing relationships are characterizable. It is thus possible to reduce all game play situations to a few categories with stable characteristics.

Keywords: handball, tactical decision, matrix of play, understanding, studentcentered approach

\section{Introduction}

Constant cooperation with partners and opposition to adversaries are at the heart of team sports, even more so in invasive team sports (Clemente et al. 2014, Gréhaigne et al. 2011). As expressed by Gréhaigne et al. (1999, p. 163), "the idea for each player is to cooperate with partners in order to better oppose the opponents either while attacking (keeping one's defense in mind) or while defending (getting ready to attack)". Thus, members of one team constantly remain in opposition to members of the other team, whether as attackers, mindful of a ball loss, or as defenders, ready to counterattack in case of a ball recovery.

In team sport, we observe that players must regularly take into account unexpected situations throughout a match. Nevertheless, in the organization, even the self-organization of the game, we find player movements that regularly recur depending on the evolution of the momentary configurations of the game. However, the regulation of this confrontation, made up of many balances and some imbalances in opposition relations, remains to be implemented by the participants and/or decoded by the adversaries. Play, time and space are at the heart of success in anything that produces or transmits movement. It is thus possible to associate players' movement in team sports and the relations among

\footnotetext{
*Assistant Professor, Manouba University, Tunisia \& Sohar University, Oman \& GRIAPS, University of Bourgogne Franche-Comté, France.

${ }^{ \pm}$Assistant Professor, Manouba University, Tunisia.

${ }^{+}$Associate Professor, Sohar University, Oman.

${ }^{\circ}$ Professor, Manouba University, Tunisia.
} 
them and with opponents with certain playing principles (Bayer 1979, Gréhaigne et al. 1989, Gréhaigne and Nadeau 2015). During a match, an unexpected response can change the configuration of the game with the aim of gaining an advantage over the opponent. This decision taken by the player(s) concerned is sometimes a surprise to the opponent and will force him to react in a predictable and anticipated way in order to get ahead. This situation is largely based on understanding the rules and principles of the game, on experience and detection of clues in the game, both from opponents and teammates (Cremonesi 2013, Zerai 2006). However, the use of handball, for boys or girls, as a means of action for teaching the principles of the game in team sports is very common in Tunisian schools. Handball is a collective activity of opposition and cooperation taking place in an interpenetrating and opposing space (Jeu 1977) where by handling a ball, the objective is to score goals in a guarded vertical target. The difference between the goals scored by each team designates the winner (Zerai 2006). Often, a classic learning of team sports consists, above all, in teaching students' technical gestures and in imposing order on the field, in the form of formal distribution of players. However, we would be tempted to say that it is just as important and maybe even more important to get players to optimally manage the mess in order to progress. So, we prefer to talk, along with Teodorescu (1965/2013), about individual and collective tactics. Individual tactics represent the set of individual actions consciously used by a player facing one or more opponents, both in attack and defense. It is therefore the conscious use on the part of a player of the most appropriate tactical and technical procedures, with the aim of achieving a partial task of the game; for example, elimination of an opponent with the help of ball control, followed by a shot on goal.

In this article, these opposition relations will be analyzed in order to try to better understand and judge the decisions in play based on the concepts of offensive and defensive matrices. The analysis of these movements should allow not only the perception of the factors contributing to regulate the game, but also the understanding of the different levels of players' regulation and their interdependence.

\section{The Matrix System in Handball}

Bayer's (1979) analysis is very close to and largely influenced by that of Mahlo (1969). For this handball specialist, the specificity of team games and sports lies in the presence at all times of partners and opponents who, through their continuous actions, modify situations and make them evolve. The author proposes, through a structural analysis, the existence of organizing principles, common to the various collective sports games. The rules and principles are intended to guide the responses and behaviors of each of the protagonists (Zerai 2011). In handball, the main constraints of the game are linked to the conditions of intervention on the ball: the ball is held in one hand and the movements are made on 3 supports. In defense, the right to charge is limited and a zone prohibited to players except for the goalkeeper exists in front of the goal. To progress, the student must overcome 
motor skill or information-related problems, essential feature of the activity: (a) making choices and solving problems in a changing social environment under significant time constraints; (b) facing a transition game with constant status changes; (c) optimally managing the power balance/imbalance (rapport de forces) between both teams (Jeannin and Cremonesi 2009).

Figure 1. Characterization of the Opposition Relationship in Handball

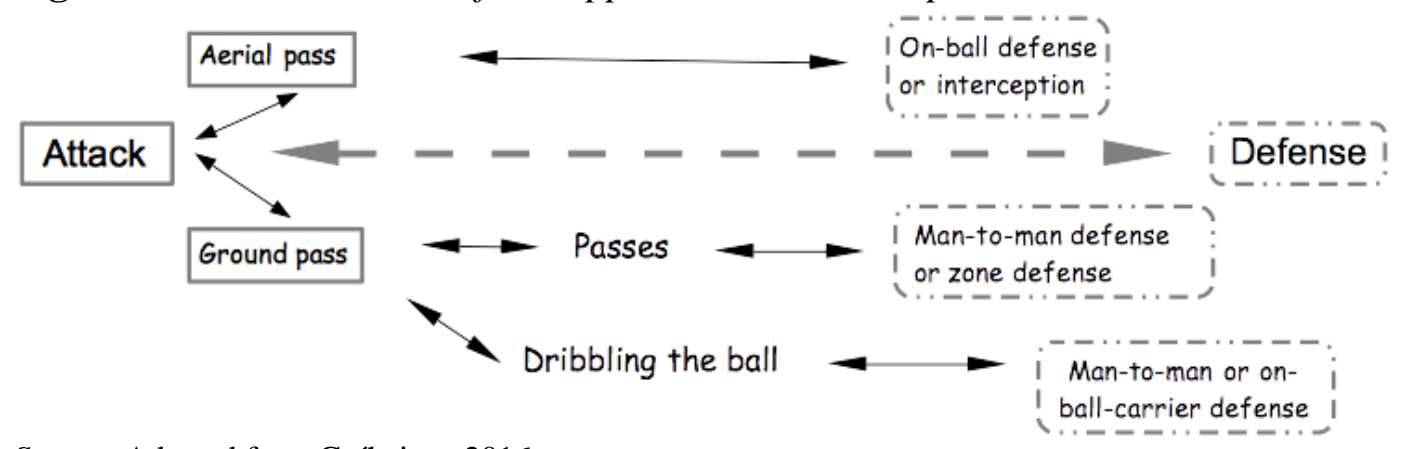

Source: Adapted from Gréhaigne 2016.

In a match, the opposition generates the unforeseen and the constant need to adapt to constraints resulting from the confrontation. Adapting consists therefore very rarely in a simple application of tactical combinations learned in training. In sequences of play where time is short and where complexity is present, the player must also know how to interpret the principles of play and the rules, how to play with them and, if necessary, how to break them or redefine them. In this sense, the player is expected to play knowingly, that is not to be dependent upon the evolution of game play but rather critical, even pragmatic at times.

Figure 1 illustrates a model of characteristic opposition links in handball. Conceived as a continuous movement, game play is synthesized into a general scaffold made of two opposing matrices of play, a "defensive matrix" and an "offensive matrix" (Deleplace 1979). This underlines that one can analyze the opposition links paying attention to the details and that it is perfectly possible to succeed in formulating them for their implementation in a conscious and methodical way, both during training sessions and during matches themselves as well.

\section{The Offensive Matrix in Handball}

The offensive matrix is in the first place the conscious choice of a strategy for penetrating the opposing defensive system according to its momentary configuration (Figure 2). This refers either to a counter-attack, or to an action aimed at rapidly attacking the momentarily weak dimension of the opposing defense or possibly an attack in the strong dimension of the opponents if one thinks it can be disorganized. 
Figure 2. Offensive Matrix: Illustrations of Game Actions Using the Concepts "Advance" and "Delay" as well as "Penetrating" and/or "Going Around"

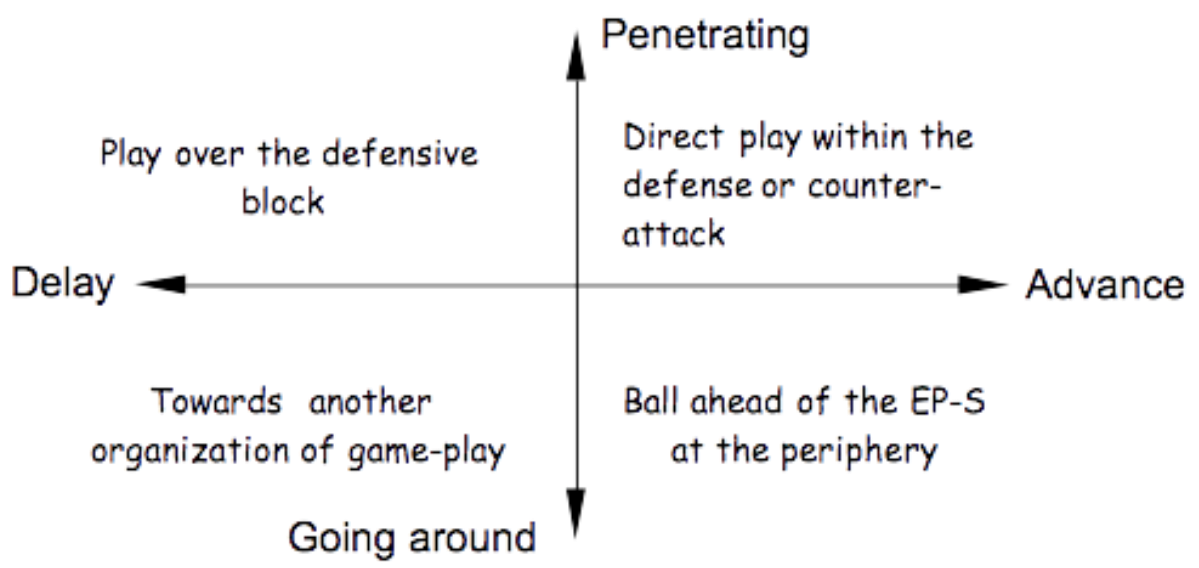

Source: Adapted from Gréhaigne 2007.

Depending on the defensive setup, the first choice is often, based on where the ball is recovered, the alternative of penetrating or bypassing, or even breaching or forcing the defensive system. It is therefore, by using players' paths and paths and trajectories of the ball, a matter of creating an imbalance by getting ahead of the opposing defensive replacement and shooting at goal. Here, several cases are to be considered.

The scoring of a goal through a counterattack determines the end of the other phases of the attack which could have been a slow passage in the attack zone and a positional attack on a defense well in barrage. In the face of such a defense, using intervals to go through defenders or going around them may bring success. Finally, in the absence of any imbalance, it is about exploiting the slightest careless fault of the opponents or an individual failure or forcing them to make mistakes. When faced with a well-established barrage defense, shooting over the defensive wall is also an appropriate response to this type of game configuration.

Any analysis of the organization of the game, both in attack and defense, has as a starting point: the incessant back and forth of the players' paths and the trajectories of the ball (Gréhaigne et al. 1999). For example, the possibility of "forcing the defensive barrage" is frequently due to its spreading out or to a regrouping due to a numerical insufficiency. Rapid ball circulation puts the defense in difficulty as the speed of a running or flying ball is usually greater than the speeds of defenders engaged in the defensive barrage. Thus, in the general movement, at every moment the question arises for the attacker whether to continue the collective movement in progress or to transform it. The increasing complexity of the matrix system is also due to the introduction of the dynamics of time in the game. From this point of view, the offensive and defensive matrices are based on dynamic principles of organization in play. In handball, as in other team sports, the objective for players is to get the ball into the goal scoring zone and score. 


\section{The Defensive Matrix in Handball}

The defensive matrix, unlike the offensive matrix, is both the simplest and more general collective organization of defense likely to stop, whatever its form, deployment or successive twists and turns, the offensive movement attempted by the opponent momentarily in possession of the ball (Deleplace 1979). The defending team achieves "defensive balance" at a given moment in the game when, at that moment, the distribution of all of its players, in relation to the opponents, to the ball and to the effective-play space (EP-S) positioning on the field, is such that it is able to respond immediately and effectively to each of the contingencies the evolution of game play may bring about in the next moment. We know that in actual game play, it happens that two moments of defensive balance may succeed one another or that a moment of defensive balance may be followed by an instant of imbalance, and vice versa. In other words, an imbalance can just as well be the consequence of a bad distribution the moment before as that of a bad use of a good distribution which existed the moment before, thus creating an imbalance. The collective defensive system is therefore built on a principle of constant instantaneous distribution of the 6 players in relation to a necessary axial coverage. In this instant distribution, the players engaged near the ball trade places with teammates of the axial cover according to the principle of circulation which responds to the uninterrupted "movement" of the whole confrontation, their purpose being to recover the ball. In this case, with the example of football, Duprat (2005) identifies four fundamental rules of defense.

- Place yourself in a barrage in relation to the ball and/or its direct opponent to protect its goal.

- Prioritize taking charge of the ball carrier, harassing him without being eliminated, pushing him to make a mistake. Wait for the right moment to get into the action of reconquest.

- Curtail or minimize play in the middle of the field and orient it to the sides to keep the ball away from the center, thus, lessening the shooting angles.

- Maintain a "combative" attitude throughout the action by putting pressure on the opponents. Exercise unwavering vigilance until the ball is recovered.

Figure 3 illustrates the main actions and configurations that can be observed in the defense using the concepts "advance" and "delay" as well as "in block" and/or "in pursuit". 
Figure 3. Defensive Matrix: Illustrations of Game Actions Using the Concepts "Advance" and "Delay" as well as "In Block" and/or "In Pursuit"

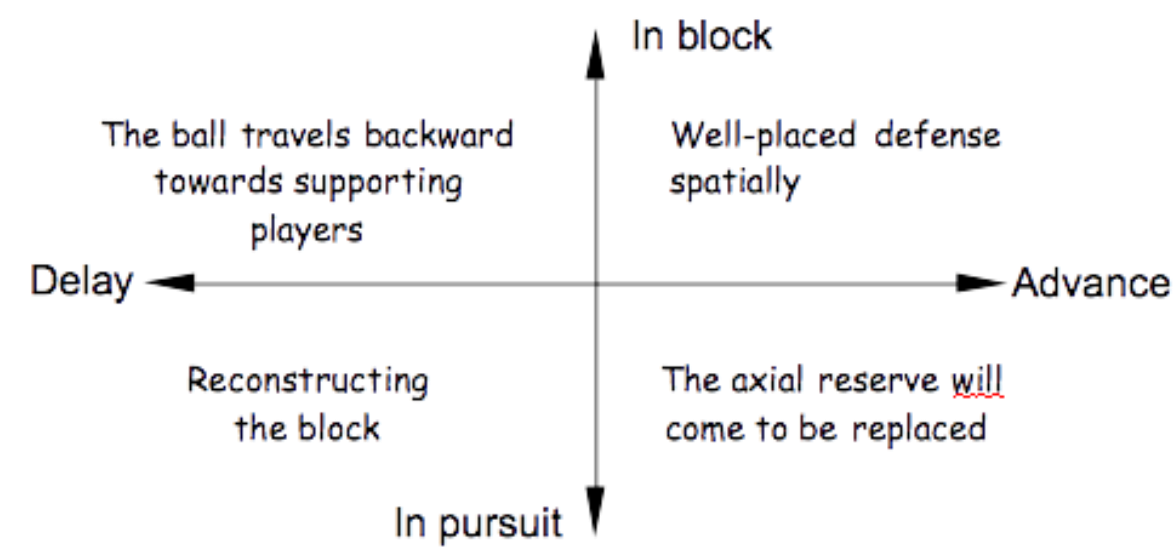

Source: Adapted from Gréhaigne 2007.

When the attack is moving the ball toward the scoring zone, should the defense be late or in pursuit, it becomes necessary to maneuver in such a way as to delay the offensive in order to allow the defenders to return and reestablish a barrage in front of the ball. In handball, time is very limited to perform these maneuvers. It should be noted that in a counterattack, at the time of a back pass while moving the ball towards the scoring zone (passing the ball in the back of the defenders), the attackers best placed to continue the counterattack are those who are back and behind the player in possession of the ball. Last and not the least, within the framework of this matrix, the goalkeeper constitutes a defensive, fundamental screen all by himself. As both last defender and first attacker, the goalkeeper actively participates in his team's play.

In a confrontational situation, any decision must be as relevant as possible regardless of the context and it only becomes valid if it can be effectively translated into action. This implies that the player actually has at his disposal a minimum of corresponding tactical and gestural responses in the form of immediately available resources.

\section{The "Tactical Matrix" of Movement Execution}

Any game activity is necessarily a tactical act whatever the player's level because it consists in solving, during action and in compliance with the primary rules of the game, a large number of problems generated by the various game situations. "The level of decision-making tactics always remain the first level, the source of everything, hence certain consequences in the way of working both in initiation and improvement" (Deleplace 1979, p. 11). The effectiveness and increasing adaptation in the execution of a movement result in a gesture-learning process itself intelligent, constantly evolving, constantly renewed over time and in opposition situations as often as possible. 
Figure 4. Constituent Elements of the Tactical Matrix of Gestural Execution

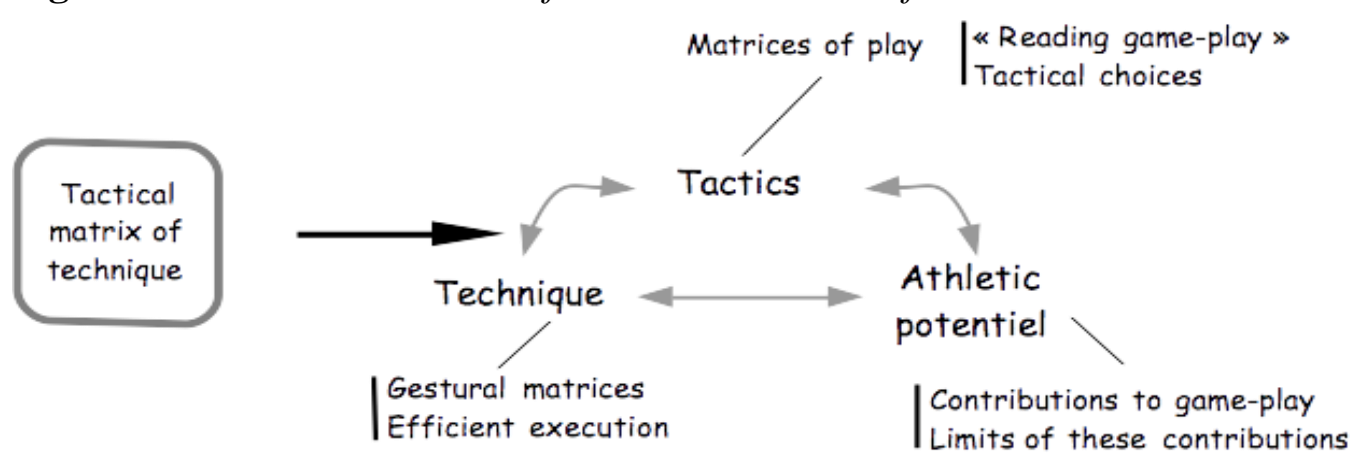

Source: Gréhaigne et al. 2005.

In a given team sport, the tactical matrix of gestural execution interrelates the tactical, technical and energetic assets of the player, in order to face a specific problem posed by the opposition. If necessary, this first level of treatment can be specified further with a deepening of these first three elements.

This tactical matrix (Figure 4) is built over time, by integrating more and more elements processed at the level of conscious control but also, most often, in the background in a non-conscious way in order to let the cognitive channel available for other tasks. Here, cognition is considered as the set of mental processes which relate to the function of knowledge and bring into play memory, language, reasoning, learning, decision-making, perception or attention, etc. In addition, the construction of this "tactical matrix" of gestural execution is the sine qua non of open gesture resources:

- promoting the achievement of the maximum number of responses as the game progresses, facilitating the fast and efficient execution of a decision imposed by the momentary balance of power;

- capable of renewal and evolution throughout the player's physical life, the way of playing changing with the evolution of age.

When one wants to work on tactical decisions, only game-play situations involving an opponent are very suitable. It is from this interpretation of the facts that the expression of the tactical matrix of gestural execution, where gestures and tactics work in symbiosis, must also be understood. In this conception of learning setups, gestures are at the same time "ready" when they are constructed and "revisited" with each new execution according to a more or less specific context. Instead of conditioning players to a particular positioning system, where information no longer plays a primary role, it is necessary to create learning situations in which the information coming from the active presence of the opponent is the basis, the guide of the action and literally becomes fundamental to the tactical resolution of the task and its execution. The links of opposition can be characterized and categorized. Thus, only working with opponents makes it possible to provide access to a "category" of situations which makes it entirely possible to work on mastering the evolution of game situations, as soon as certain similar conditions appear (Zerai et al. 2013, 2020). 
Finally, it is good to specify that this matrix serves as a common thread for the decisions taken in the game where the athletic aspects are not to be neglected (Bouthier 1993). Together with individual tactics, it is assumed that the intervention of cognitive processes in the use of the objects of technique is decisive. Taking into account the tactical matrix of gestural execution is therefore choosing the individual tactic, well executed, tactically correct and performed at the right time depending on the evolution of the game. Engaged in the game, the player adjusts not only to what he sees, but also to what he foresees because he also decides according to the probabilities of evolution of the game with, as much as possible, an overall appreciation and instantaneous minimum of useful information. It is, therefore, a complex and continuous entanglement of data but few that the player collects in relation to his knowledge and motor skills already available or in the process of evolving. Thus, the player frequently faces a triple uncertainty: (a) a temporal one, referring to the duration of the action and its speed; (b) a spatial one, as to where the action is located and whether it is in contraction or expansion; (c) an informational one, about the probability of evolution of the momentary configuration of the game.

\section{Movement in the Game}

In handball, the dynamics of the game offer rapid changes in game situations calling for fast reactions and great mobility. The general movement of the players and the ball constitutes a dynamic network constantly in transformation where the different sequences of play engender one in the other (Zerai and Gréhaigne 2020).

In the course of the game, the double-acting organization (Deleplace 1966, 1979, Gréhaigne and Dietsch 2015) organically links offense and defense, emphasizing the immediacy of the transition from attacker to defender (Figure 5). For this organization, it should be noted this particularity of handball which allows to play "back-to-back" to the zone. Under these conditions, it is absolutely essential that the basic organization that constitutes the defensive matrix also respond to the possibility of a counter-attack situation. This means that these fundamental elements do indeed constitute an organizational "unity-totality" with a double effect, constantly implemented by the simultaneity and the succession of individual initiatives (Deleplace 1979, p. 45).

Figure 5. Didactical Model of Game Play Based on an Analysis of Configurations of Play in Handball

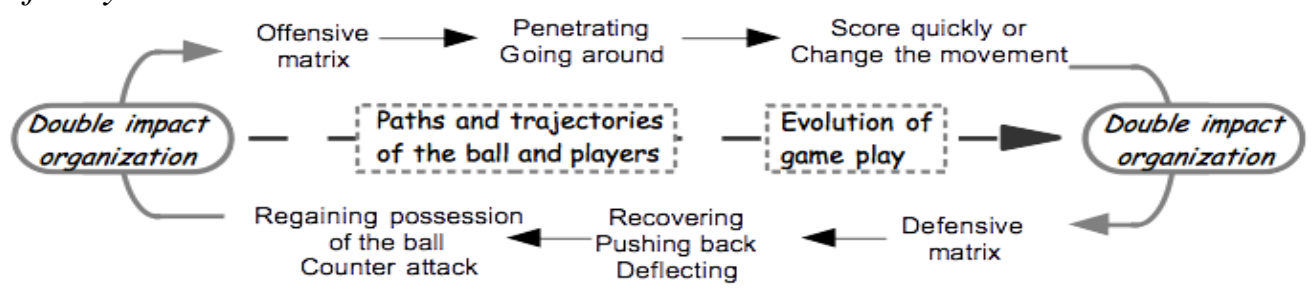

Source: Gréhaigne et al. 2010. 
One must therefore be able to move from the defensive phase to the offensive phase (and vice versa) in a very short time and at any position by making the appropriate choices. This is an important job to do at the learning level during training. When you are in defense, you must already have one or more game plans that allow you to launch the counter-attack as soon as the ball is recovered with the help of players placed in front. If one is in attack, the players placed in support, that is to say behind the ball carrier, must also consider that the actions they plan to carry out also constitute the first line of defense in the event of a ball loss. A player must constantly deploy a critical tactical analysis, while adapting to the tactical initiatives of his partners and opponents. This approach to team confrontation makes it possible to understand team sports from a systemic perspective where opposition relations are the basis of the game (Gréhaigne 1989).

Thus, in play in action, players are faced with the immediacy of the transition from the role of attacker to that of defender. This reversibility of situations represents a fundamental aspect of team sports in relation to the fact that both teams attack and defend in turn. Therefore, there is always a part of defense in the attack and a part of attack in the defense (Figure 5). It follows that we can speak of a real "co-construction" of the attack/defense system, this system being made and unmade as the action takes place. This type of team organization aims, when in defense, at launching the attack as soon as the ball is recovered with the help of the players placed in support. If attacking, supporting players should think of themselves as the first defense against the counterattack if the ball is lost and prepare accordingly. The transition into the double-acting situation is often a key moment, especially during the recovery of the ball because in this phase of the game, the last attack becomes defense and must be reorganized: either oppose the front of the ball (recoil brake) to try to recover the ball quickly; either retreat or breakaway to reconstitute the defensive curtains in the depth of the court; either, if the defensive curtains are in place, oppose the penetrations of the opponent. As for defense having turned into attack, choices are: either a fast counterattack with few ball exchanges and little time to succeed; either a rapid breach if the defense is only partly in barrage, hoping for a shot on goal despite time running out; or, in the event of failure of the action towards the goal, a tactical switch to other attack options where the conservation of the ball makes it possible to wait for another opportunity (Gréhaigne et al. 2009).

In a socio-semio-constructivist conception (Wallian and Gréhaigne 2004) of learning handball (Darnis 2019, Zerai 2015), it is therefore necessary to conceive the organization of the game as a totality which amounts to thinking of the attack/defense and defense/attack together where, at any moment, everything can change. Of course, this abstraction and this meaning given to the confrontation emphasizes (a) the defensive precautions to be considered in the present attack movement (making sure to conserve the ball) and (b) the offensive anticipation to be considered in the current defense (preparing to recapture the ball and counterattack). It is therefore appropriate to consider the phases of the game as deeply intertwined, even entangled, in which micro-states of balance and imbalance succeed one another (Zerai et al. 2013). 
As learning increases, one observes an improvement in the refinement of the tactical matrix of skill execution and a greater speed in the final phase of orderly attacks. We also note that the counter-attack is systematically sought and that defenders become more offensive to counter this type of movement and thus try to recover the ball. All teams have several types of defenses depending on the opponents encountered. Defenses are characterized by a great mobility of players (Roche and Belmessaoud 2016).

After these considerations on what constitutes a good level of play, we will come to the characteristics of a work cycle (lesson sequence) with beginner players from Thala high school (Zerai 2011) to see how these opposition links constitute indeed the background. of the educational process.

\section{Young Tunisian Girls and Handball}

For young Tunisian girls in school programs, the teaching of team sports/ games and handball begins in high school. We submit that if these lessons began in middle school, or even in elementary school, female students' relationships with their body would develop differently. Team sports could thus contribute to the construction of new motor skills mastery. These ideas come from a long cycle of eleven handball lessons (Zerai 2015) using a small-sided games approach and the debate of ideas. Here, students were asked to organize themselves collectively and individually to observe, analyze and develop action projects in order to defeat an opposing team. Then, it was a matter of evaluating and regulating this project, the debates of ideas constituting the common thread to analyze the evolution of the game.

For these beginners, learning consisted in building new knowledge and motor skills because they had little technical background (and that is saying something). During this learning cycle, the gradual construction of individual tactics provided students with capacities enabling them to achieve progress. The new motor skills did not remain isolated, but maintained close relationships with other knowledge (information, tactics, social skills, self-knowledge, etc.). At first, decisions made in the game seemed neither planned nor guided by a project. Students had difficulty passing the ball and often lost it. Getting closer to the goal to take shots was a problem, the ball being very frequently intercepted in the midfield. As a result, the retention of the ball was short (loss of balls, hits or fouls) and the few attempts to shoot from distance were almost all doomed to failure. The girls had great difficulty in matching what they wanted to do with regard to their own motor skills.

This cycle, with a systematic recourse to opposing situations, generated a lot of progress because it was not only a matter of performing techniques in the strict sense of the term but, also, of analyzing the conditions of doing and of knowing by doing. In other words, the results obtained reflected all the elements that girls had learned to master and these transformations had largely reorganized their resources. From an acted-out situation, the girls were called upon to put into words and verbalize in order to build effective rules of action making it possible to overcome the obstacles encountered in the game. The use of handball in physical and sports 
education is appropriate because it allows, relatively easily, exchanges and a coconstruction with others. In addition, we can affirm that if tactical skills are built in part thanks to these cognitive tools, verbal interactions between peers greatly help their development.

\section{Conclusion}

From our point of view, living tactical knowledge and motor skills, built in the game from the usual motor skills in relation to simple rules of the organization of the game, constitutes the bases of a renewed didactics of team sports and games at school. In team sports, it is game play that comes first with the right decisions made at the right time for the players to keep things running smoothly. The principles of play (theoretical foundations regarding the functioning of the opposing forces) establish the bases of the logic of the game in the systematic taking into account of the opposition relationship between an attack and a defense (Duprat 2019). The essence of the game is to simultaneously manage the conservation of the ball for his team and the hitting of the opponent's goal; for the opponents, it will be about recovering the ball and defending their own goal. From this point of view, analyzing, explaining the opposition and using it as a source of any reflection makes it possible to design effective learning situations in terms of player development. So, it will be necessary to reflect, discuss and exchange in the future on current questions concerning the forms of evolution of the game and on the transformations of players in the context of complex learning.

\section{Acknowledgments}

The authors thank Paul Godbout for his help in editing the paper in English.

\section{References}

Bayer C (1979) L'enseignement des jeux sportifs collectifs (Teaching team sports). Paris: Vigot.

Bouthier D (1993) L'approche technologique en STAPS (Technological approach in S.T.A.P.S.) Doctoral Dissertation in S.T.A.P.S. Paris-Sud Orsay University.

Clemente FM, Martins FML, Mendes RS, Figueiredo AJ (2014) A systemic overview of football game: the principles behind the game. Journal of Human Sport \& Exercise 9(2): 656-667.

Cremonesi B (2013) Les règles au service des apprentissages (Rules at the service of learning). Contrepied Special Edition no. 6, 13-15.

Darnis F (2019) Une approche socio-constructiviste en EPS (Socio-constructivist approach in the teaching of physical education). Doctoral Dissertation (Unpublished). University of Bordeaux.

Deleplace R (1966) Rugby. Paris: Colin-Bourrelier.

Deleplace R (1979) Rugby de mouvement - Rugby total (Rugby in movement - Total rugby). Paris: Éducation Physique et Sport. 
Duprat E (2005) Approche technologique de la récupération du ballon lors de la phase défensive en football, contributions à l'élaboration de contenus de formation innovants. (Technological approach to the recovery of the ball during the defensive phase in football, contributions to the development of innovative training content). Unpublished Doctoral Thesis. ENS: Cachan.

Duprat E (2019) L'opposition au cœur de l'analyse en spot collectif (The opposition at the heart of the analysis of team sports). eJRIEPS 40: 26-50.

Gréhaigne J-F (1989) Football de mouvement: vers une approche systémique du jeu (Movement football. Towards a systemic approach to play). Doctoral Dissertation (Unpublished). Université de Bourgogne.

Gréhaigne J-F (Ed.) (2007) Configurations du jeu, débat d'idées et apprentissage des sports collectifs (Configurations of play, debate of ideas and learning of team sports). Besançon: Presses of the University of Franche-Comté.

Gréhaigne J-F (2016) Le défi du football dans l'enseignement scolaire (The challenge of football in school education). Revue EP\&S 370: 44-46.

Gréhaigne J-F, Billard M, Guillon R, Roche J (1989) Vers une autre conception de l'enseignement des sports collectifs (Towards another conception of the teaching of team sports). In G Bui-Xuan, P Boyer, P Chifflet Y Leziart (eds.), Methodology and didactics of physical education and sports, 201-216. Paris: AEEPS.

Gréhaigne J-F, Caty D, Godbout P (2010) Modelling ball circulation in invasion team sports: a way to promote learning games through understanding. Physical Education and Sport Pedagogy 15(3): 257-270.

Gréhaigne J-F, Dietsch G (2015) Quelques aspects théoriques de la didactique des sports collectifs (Some theoretical aspects of team sports didactics). eJRIEPS (Special Issue $1)$.

Gréhaigne J-F, Godbout P, Bouthier D (1999) The foundations of tactics and strategy in team sports. Journal of Teaching in Physical Education 18: 159-174.

Gréhaigne J-F, Godbout P, Zerai Z (2011) How the "rapport de forces" evolves in a soccer match: the dynamics of collective decisions in a complex system. Revista de Psicología del Deporte, 20 (2) 747-764.

Gréhaigne J-F, Nadeau L (2015) Le mouvement, la dynamique du jeu et l'espace-temps (The movement, the dynamics of game play and space - time). eJRIEPS (Special Issue 1): 79-91.

Gréhaigne J-F, Richard J-F, Griffin L (2005) Teaching and learning team sports and games. New York: Routledge Falmer.

Gréhaigne J-F, Zerai Z, Caty D (2009) Prototypic configurations of play in handball in physical education: a strategy to promote student understanding in team sports. In $\mathrm{T}$ Hopper, J Butler, B Storey (eds.), TGFU simply good pedagogy; understanding a complex challenge, 51-62. Physical and Health Education Canada.

Jeannin P, Cremonesi B (2009) Handball. Contrepied. Retrieved from: https://www.con trepied.net. [Accessed 29 January 2021]

Jeu B (1977) Le sport, l'émotion, l'espace (Sport, emotion, space). Paris, France: Vigot.

Mahlo F (1969) L'acte tactique en jeu (Tactical act in play). Paris, France: Vigot.

Roche L, Belmessaoud S (2016) Video analysis at the service of handball performance: current uses and perspectives. Approches du Handball 154: 52-57.

Teodorescu L (1965/2013) Principes pour l'étude de la tactique commune aux jeux sportifs collectifs (Principles for the study of tactics common to team sports-games). Revue de la S.I.E.P.E.P.S. 3: 29-40.

Wallian N, Gréhaigne J-F (2004) Vers une approche sémio-constructiviste des apprentissages moteurs (Towards a semio-constructivist approach to motor learning). 
In G Carlier (ed.), Si l'on parlait du plaisir d'enseigner l'éducation physique, 167179). Montpellier: AFRAPS.

Zerai Z (2006) How do girls learn in handball? Contribution of verbalization. Master degree in Didactics of Physical and Sports. Tunis: ISEFC.

Zerai Z (2011) Apprentissage du handball chez les jeunes filles tunisiennes et françaises; apport de la verbalisation (Learning handball for young Tunisian and French girls; Contribution of verbalization). Doctoral Dissertation (Unpublished). University of Franche-Comté, Besançon.

Zerai Z (2015) Effect of the debate of ideas on learning handball among beginners: the case of young Tunisians. eJRIEPS 35: 86-104.

Zerai Z, Gréhaigne J-F (2020) Action in project, learning through understanding and observation setting in the lessons of team sports. International Journal of Physical Education LVII(3): 11-20.

Zerai Z, Gréhaigne J-F, Godbout P (2013) Configurations of play in invasion team sports and learning by analogy. International Journal of Physical Education L(1): 18-28.

Zerai Z, Gréhaigne, J-F, Godbout P (2020) Student understanding and learning in team sports: understanding through game-play analysis. Athens Journal of Sports 7(4): 215-234. 
